We welcome letters to the Editor concerning articles which have recently been published. Such letters will be subject to the usual stages of selection and editing; where appropriate the authors of the original article will be offered the opportunity to reply.

Letters should normally be under $\mathbf{3 0 0}$ words in length, doublespaced throughout, signed by all authors and fully referenced. The edited version will be returned for approval before publication.

C2005 British Editorial Society of Bone and Joint Surgery doi:10.1302/0301-620X.87B7 \$2.00

J Bone Joint Surg [Br] 2005;87-B:1024-5.

\section{The management of slipped capital femoral epiphysis}

Sir,

We read with interest the article by Uglow and Clarke ${ }^{1}$ in the July 2004 issue entitled 'The management of slipped capital femoral epiphysis'. While we found most of the article to be an excellent review and discussion, we must take exception to the recommended management of the unstable slipped capital femoral epiphysis as described, as well as the proposed treatment algorithm.

Initially, the authors make references to Jones (personal communication) as the basis for delaying definitive treatment for severe unstable slipped capital femoral epiphysis for three weeks while temporising the patient in skin traction and bed rest. Apparently, the authors feel that this time period may allow some gradual reduction of the deformity that may facilitate in situ screw fixation, as well as allow resolution of the compromised blood supply, thereby minimising the potential for avascular necrosis. Finally, they appear to recommend osteotomy of the femoral neck for those patients whose slipped epiphyses do not reduce adequately during the three-week window.

We are unclear from where this recommendation arises, as we are not aware of any literature that supports it, nor have we ever heard this expressed previously in any other monograph or review article. Our experience in the management of 75 to 100 patients annually with a stable or unstable slipped capital femoral epiphysis has not shown such management to be realistic, necessary or beneficial. In the vast majority of unstable slipped capital femoral epiphyses, urgent but not emergency management is appropriate. The deformity in such patients generally will reduce to the stable position with general anaesthesia and simple positioning of the patient on the fracture table or radiolucent table of choice. In those patients whose slipped epiphyses do not reduce significantly, we have found that in situ pinning can be performed in the presence of almost any grade of displacement. Certainly, routine femoral neck osteotomy as recommended by the authors for those that do not reduce to grade I or grade II is rarely necessary in our experience. Subsequent intertrochanteric flexion derotational osteotomy may be performed at a later date in those patients requiring improved mechanical alignment. While this procedure will not achieve the same level of correction, it is safer as far as risk of avascular necrosis is concerned. Complete correction, while desirable, may not be necessary, as we know from the long-term natural history study generated at the University of Iowa. ${ }^{2}$ Finally, later surgical dislocation and femoral neck reshaping as described by Ganz et $\mathrm{al}^{3}$ may be beneficial in some patients. doi:10.1302/0301-620X.87B7.16660

\section{J. F. MOONEY, III, MD \\ Children's Hospital of Michigan, Michigan, USA.}

D. A. PODESZWA, MD

Children's Medical Center Dallas

Dallas, USA.

1. Uglow MG, Clarke NMP. The management of slipped capital femoral epiphysis. J Bone Joint Surg [Br] 2004;86-B:631-5.

2. Carney BT, Weinstein SL, Noble J. Long-term follow-up of slipped capital femoral epiphysis. J Bone Joint Surg [Am] 1991;73-A:667-74.

3. Ganz R, Gill TJ, Gautier E, et al. Surgical dislocation of the adult hip. J Bone Joint Surg [Br] 2001;83-B:1119-24.

\section{Author's reply:}

Sir,

The authors would like to thank Drs Mooney and Podeszwa for their interest in our article and for their comments regarding the management of a grade III slipped capital femoral epiphysis. The number of patients to which this discussion refers is remarkably few. All patients with grade I and II slips will be treated with in situ screw fixation, as will the vast majority of grade III cases. We have tried to address the management of the few patients with a severe acute displaced grade III slip.

Patients presenting within the first 24 hours will proceed to the operating theatre and appropriate repositioning on the operating table will allow screw fixation in the vast majority. If screw fixation is not possible without penetration of the posterior cortex of the neck and subsequent damage to the vascular supply, then the operating surgeon must choose between a cuneiform osteotomy immediately or attempting a trial of traction as described by Dietz. ${ }^{1}$ Radiographs may be taken during the period of traction and if any improvement is observed, then screw fixation can be undertaken without further delay. If no improvement occurs until the third week, such that screw fixation in situ is deemed not possible, then a cuneiform osteotomy of the neck would be performed.

As Drs Mooney and Podeszwa stated, "in situ pinning can be performed in the presence of almost any grade of displacement". There are, on occasion, cases that cannot be treated with in situ 
fixation and it is in these cases that we would proceed with a cuneiform osteotomy.

doi:10.1302/0301-620X.87B7.16661

M. UGLOW, FRCS(Tr \& Orth), Consultant Orthopaedic Surgeon

N. M. P. CLARKE, ChM, FRCS,

Consultant Orthopaedic Surgeon

Southampton General Hospital,

Southampton, UK.

1. Dietz FR. Traction reduction of acute and acute on chronic slipped capital femoral epiphysis. Clin Orthop 1994;302:101-10.

\section{Foot function after subtalar distraction bone block arthrodesis}

Sir,

I read with interest the article of Rammelt et al ${ }^{1}$ in the July 2004 issue entitled 'Foot function after subtalar distraction bone block arthrodesis'. There appear to be inconsistencies in the number of patients assessed.

The authors give the following breakdown: excellent in nine patients (29\%); good in $18(58.1 \%)$; fair in eight $(25.8 \%)$; and poor in two $(6.5 \%)$ for a total of 37 patients.

As the article pertains to only 31 patients, there is obviously an error and I would appreciate it if the authors could provide us with the corrected numbers.

doi:10.1302/0301-620X.87B7.16658

J. J. VAN NIEKERK, MB, CHB, MMED (Chir)

Morningside Clinic,

Johannesburg, South Africa.

1. Rammelt S, Grass R, Zawadski T, Biewener A, Zwipp H. Foot function after subtalar distraction bone block arthrodesis: a prospective study. J Bone Joint Surg $[\mathrm{Br}]$ 2004:86-B:659-68.

\section{Author's reply:}

Sir,

We thank Dr. van Niekerk for his interest in our article. There were 12 patients $(38.7 \%)$, who subjectively rated their result as 'good'. Because of a typing error the number 18 appeared in the manuscript and a wrong percentage was calculated from that. The other numbers were correct. While we regret that error, we feel it does not change anything with respect to the overall results and the conclusions drawn from it.

doi:10.1302/0301-620X.87B7.16659

S. RAMMELT, MD

University Hospital 'Carl Gustav Carus'

Dresden, Germany

\section{Acetabular dysplasia after treatment for developmental dysplasia of the hip}

Sir,

I read with interest the article by Albinana et $\mathrm{al}^{1}$ in the August 2004 issue entitled 'Acetabular dysplasia after treatment for developmental dysplasia of the hip'. I am puzzled about the mean age of reduction in the closed group which was 18 months and in the open group it was eight months. I wonder if the age should be the other way round?

doi:10.1302/0301-620X.87B7.16662

S. IBRAHIM

National University Hospital,

Kuala Lumpur, Malaysia.

1. Albinana J, Dolan LA, Spratt KF, et al. Acetabular dysplasia after treatment for developmental dysplasia of the hip. J Bone Joint Surg [Br] 2004;86-B:876-86.

\section{Author's reply:}

Sir,

We thank Dr Ibrahim for his interest in our paper. The mean age at reduction in the open reduction group is indeed eight months compared to 18 months in the closed reduction group. This is because of two factors: the closed reductions were generally performed early in the series prior to the advent of widespread, conscientious screening programs for the diagnosis of developmental dysplasia of the hip. The open reductions were generally performed later in the series, when developmental dysplasia of the hip was diagnosed earlier and our approach to development dysplasia of the hip became less conservative.

doi:10.1302/0301-620X.87B7.16663

\section{S. L. WEINSTEIN, MD}

L. A. DOLAN, PhD

University of Iowa Health Care,

Iowa City, Iowa, USA. 